\title{
Oficinas Itinerantes de Scratch e Computação Desplugada para Professores como apoio ao Ensino de Computação - um Relato de Experiência
}

\author{
Thiago Reis da Silva1, Glaúber Galvão de Araujo ${ }^{1}$, Eduardo Henrique da Silva \\ Aranha ${ }^{1}$ \\ ${ }^{1}$ Programa de Pós-Graduação em Sistemas Computacionais - PPgSC \\ Universidade Federal do Rio Grande do Norte - UFRN \\ Caixa Postal 1524 - Campus Universitário Lagoa Nova - CEP 59072-970 - Natal/RN - \\ Brasil \\ \{trsilva.si, glauber.galvao\}@gmail.com; eduardoaranha@dimap.ufrn.br
}

\begin{abstract}
This paper reports an experience in implementing workshops for teachers from local schools of Rio Grande do Norte. The aim of the workshops was to create opportunities for educators to use Scratch software as a tool to assist them in teaching practice and also fun activities to teach computing concepts through Computing Unplugged. The workshops presented significant results. Participating teachers emphasized the importance of those moments for their continuing education and expressed interest in other meetings for further applications and programming knowledge.
\end{abstract}

Resumo. Este artigo relata uma experiência vivenciada na aplicação de oficinas para professores da rede estadual e municipal de ensino do Rio Grande do Norte. O objetivo das oficinas foi oportunizar, para educadores, a utilização do software Scratch, como ferramenta auxiliar na prática docente e também de atividades lúdicas para ensinar computação através da Computação Desplugada. Os resultados foram significativos e os professores participantes ressaltaram a importância de momentos como este, para sua formação continuada e também manifestaram o interesse de outros encontros para aprofundar as aplicações e a programação.

\section{Introdução}

A ampliação na oferta de oportunidades de aprendizagem dos fundamentos da Ciência da Computação foi definida como estratégica para o progresso científico e tecnológico de qualquer país tanto por um relatório apoiado pela Association for Computing Machinery - ACM [Denning, 2004], entidade mundial que discute os rumos da Ciência da Computação, quanto por uma recomendação conjunta divulgada pela Sociedade Brasileira de Computação - SBC e o Ministério da Educação - MEC [SBC, 2011]. O desenvolvimento do Pensamento Computacional ou Computational Thinking entre os mais diversos perfis acadêmicos seria uma questão de base para a formação de profissionais e cidadãos em melhores condições de empregarem as tecnologias na transformação do seu próprio cotidiano [Sant'Ana e Neves, 2012].

No entanto, no Brasil, o aprendizado dos fundamentos da Ciência da Computação é reservado apenas àqueles que optam por cursos de graduação na área 
[França, Silva e Amaral, 2012]. Em outros países como os Estados Unidos, Canadá e Israel, o ensino de programação já é aplicado também no ensino básico. O Grupo de Licenciatura em Computação (GT-3) da Sociedade Brasileira de Computação (SBC) tem suportado a proposta de incluir conteúdos de informática no Ensino Médio [Pereira Junior et. al., 2005], apesar disso ainda não ser uma realidade.

Para que esse movimento se desenvolva, contudo, primeiro é necessária à preparação dos professores de outras disciplinas para aplicarem esses conceitos em sala de aula. Assim, a fim de colaborar com as pesquisas na área, foram realizadas quatro oficinas com o uso da ferramenta de programação visual, conhecida por Scratch e quatro oficinas com uma abordagem conhecida por Computer Science Unplugged (em tradução livre "Computação Desplugada") com a participação de 103 (cento e três) professores da rede estadual e municipal de ensino do Rio Grande do Norte. O propósito deste estudo é apresentar uma noção relativamente nova sobre a temática e a inserção do pensamento computacional nas escolas do estado. Este artigo também relata as experiências obtidas na realização destas oficinas.

Portanto, este trabalho está organizado na seguinte forma: na Seção 2 é apresentada a fundamentação teórica, na Seção 3 é exposta a organização da oficina, na Seção 4 é abordada os resultados destas experiências e, por fim, na Seção 5 são reportadas as conclusões finais e as perspectivas de trabalhos futuros.

\section{Fundamentação Teórica}

Essa seção irá apresentar uma breve fundamentação sobre o Scratch e a abordagem CSUnplugged (Computação Desplugada).

\subsection{Scratch}

O Scratch é uma linguagem de programação visual, desenvolvido pelo Media Lab do Instituto de Tecnologia de Massachusetts (MIT), inspirada no Lego, que possibilita a criação de histórias interativas, animações, simulações e jogos, e o compartilhamento dessas criações na $W e b$.

O propósito do Scratch é introduzir a programação para quem não tem experiência no assunto. A programação é feita arrastando-se blocos de comandos que devem ser encaixados uns aos outros [França e Amaral, 2013].

\subsection{Computação Desplugada}

A Computer Science Unplugged ou Computação Desplugada é o conceito que se baseia na não utilização do computador para o ensino de fundamentos da Ciência da Computação [Bell, Witten e Fellows, 2011]. A vantagem desse método é a possibilidade de se trabalhar a computação em lugares remotos que não disponham de infraestrutura (energia elétrica, hardware ou software) necessária para a utilização de computadores e podem até ser ministradas por não especialistas em computação.

A Computação Desplugada é um método de ensino atraente por criar circunstâncias que exploram ações relacionadas ao trabalho em equipe, a resolução de problemas e a criatividade. 


\section{Organização da Oficina}

A organização das oficinas compreendeu um conjunto de etapas que incluem a formação da equipe, o levantamento bibliográfico, o planejamento e preparação das oficinas, a elaboração de instrumentos de avaliação e a realização das oficinas. Estas etapas são detalhadas a seguir.

A equipe é composta por um professor doutor, dois alunos de doutorado, uma aluna de mestrado e uma bolsista de graduação. Os integrantes já possuem envolvimento com o grupo de pesquisa e tem conhecimentos relacionados com a proposta das oficinas.

O levantamento bibliográfico foi realizado contemplando o uso do Scratch e da Computação Desplugada no ambiente escolar. Depois foram desenvolvidas as atividades relativas à oficina, incluindo a preparação dos recursos didáticos a serem utilizados em aulas expositivas e as atividades a serem realizadas na prática, essa atividade corresponde ao planejamento e preparação das oficinas. Com o objetivo de avaliar as oficinas, foi disponibilizado um questionário para que os professores relatassem o que acharam da oficina.

Foram realizadas quatro oficinas, sendo uma no Instituto Federal do Rio Grande do Norte-IFRN, Campus Mossoró-RN, duas no Instituto Metrópole Digital-IMD, em Natal e outra no Instituto Federal do Rio Grande do Norte-IFRN, Campus João CâmaraRN. Cada oficina teve a duração de aproximadamente 4 horas e foram executadas como parte do Curso de Aperfeiçoamento em Docência na Escola de Tempo Integral (parceria MEC/UFRN). Compareceram às oficinas 103 (cento e três) professores atuantes no programa Mais Educação ${ }^{1}$.

As oficinas iniciaram com a apresentação do grupo de pesquisadores e os objetivos da oficina. Em seguida uma breve explicação dos conteúdos que seriam apresentados e das atividades que seriam realizadas.

Durante a interação dos professores na realização das atividades, os pesquisadores fizeram observações e anotações de aspectos relevantes para a avaliação da oficina como um todo. Ao final, os professores responderam os questionários.

\section{Resultados}

O trabalho descrito neste artigo é o desdobramento de um projeto que vem sendo desenvolvido desde o início de 2014, inicialmente com professores das escolas públicas do RN e depois replicado com alunos em sala de aula, que tem como objetivo introduzir o pensamento computacional em escolas do ensino básico do estado. As subseções a seguir apresentam os resultados das quatro primeiras oficinas ministradas aos professores.

\subsection{A oficina de programação com Scratch}

\footnotetext{
${ }^{1}$ O programa Mais Educação do Ministério da Educação tem como objetivo induzir a ampliação da jornada escolar e a organização curricular das escolas na perspectiva da educação integral.
} 
A escolha do Scratch foi motivada por ser um software de uma sintaxe fácil, baseado em blocos de arrastar e soltar (montar), em que é possível criar estórias, animações e jogos simples.

As oficinas estimularam o ensino baseadas no conceito de colaboração, no qual os professores possam trabalhar com outros professores no processo criativo de ensino e aprendizagem, e a na reflexão, revendo, repensando e implantando práticas criativas e lúdicas para fortalecer o processo de aprendizagem dos alunos.

Esta oficina dedicou-se a apresentar a interface gráfica do ambiente, explorando os grupos de blocos por função e introduzindo os conceitos de sequência e laços na construção de estórias (programas) simples. Foram introduzidos também os conceitos de eventos e condicionais, adicionando a dimensão interativa aos programas desenvolvidos pelos participantes. Além disso, foi trabalhado o manuseio de sons, importar imagens ou desenhar seus próprios personagens nas estórias animadas desenvolvidas pelos professores.

O grupo propôs ainda atividades de familiarização com o Scratch e apresentou seus comandos aos professores; na sequência, o desenvolvimento da oficina com atividades que visaram explorar a aplicabilidade dos comandos e que tinham como motivo a construção de uma estória, estruturada de forma colaborativa e cooperativa, a qual foi utilizada como auxílio para a programação, que empreende os comandos que o software oferece. Essa atividade foi realizada passo a passo com os professores, cada passo que o instrutor realizava, os professores faziam o mesmo, em caso de dúvida era acionado um dos integrantes do grupo para auxiliar os professores.

Por fim, o momento de encerramento promoveu a discussão e avaliação sobre a experiência da oficina e incentivou os professores a organizarem oficinas de Scratch nas escolas. Também nesse momento foi solicitado aos participantes que respondessem a um questionário de avaliação da oficina. Os questionários foram tabulados e os dados estáticos foram calculados. Os resultados desses questionários serão descritos nas subseções 4.1 .1 e 4.1 .2 a seguir.

\subsubsection{Avaliação Qualitativa}

O grupo de participantes da oficina era composto por vários professores de áreas de conhecimento distintas, entre elas, pedagogia, geografia, física, história, matemática e português. Nas atividades propostas, percebeu-se a participação e colaboração dos professores, no sentido de interagir, de questionar, de sugerir e de elaborar suas estórias construídas de forma interativa. Os professores da rede estadual de Natal $(\mathrm{RN})$, por exemplo, demonstraram interesse na possibilidade de aplicação do Scratch para algumas disciplinas, principalmente matemática e um professor convidou o grupo para realizar essas oficinas nas escolas, com os alunos.

Em geral, no que diz respeito às discussões sobre a aplicação desta oficina, foi possível perceber que os professores com formação na área de física e matemática sentiram-se mais atraídos em utilizá-la pelo potencial da ferramenta, podendo ser utilizados, por exemplo, na aritmética e cinemática.

Os conceitos relacionados à sequência e laços na construção foram os assuntos nos quais os professores encontraram mais dificuldades, fato já esperado pela equipe do projeto. Alguns professores tinham pouco conhecimento de informática básica e para 
outros foi o primeiro contato com os elementos de programação. Mesmo assim, os resultados foram significativos e os professores destacaram vários pontos positivos da oficina, entre eles: (i) as dicas que estamos levando para as escolas; (ii) possibilidade de criar o próprio jogo; (iii) a utilidade da ferramenta para aprendizagem dos alunos; (iv) possibilidade de trabalhar os conteúdos através de jogos; (v) possibilidade dos próprios alunos criarem os jogos; (vi) trabalhar a criatividade, a motivação e o lúdico; (vii) a possibilidade de criar um jogo dando ênfase as reais necessidades do alunado; (viii) possibilidade de deixar as aulas mais atrativas.

No que tange aos aspectos negativos, os professores reportaram, as dificuldades pessoais de lidar com as mídias, e a maioria relatou o pouco tempo para a realização das atividades. Foram vários os comentários sugerindo que essa oficina tivesse um segundo momento, para que os mesmos pudessem aplicar mais alguns conteúdos.

Ao encerrar as atividades, a oficina foi avaliada pelos participantes, sendo expostas as principais ideias que surgiram no seu decorrer. Os professores ressaltaram a importância de se proporcionar momentos como este, pois não conheciam o software. Manifestaram ainda, a necessidade de mais encontro e o aumento da carga horário da oficina para aprofundar os seus conhecimentos.

Por fim, ficou clara a dificuldade de alguns professores no primeiro contato com um computador, devido às dificuldades com os conhecimentos de informática básica. Dessa forma, se ratifica a importância de possibilitar formações complementares a esses professores.

\subsubsection{Avaliação Quantitativa}

As análises realizadas permitiram descobrir indícios úteis para melhoria dos aspectos pedagógicos e tecnológicos na elaboração e execução das oficinas.

Os dados desse questionário foram analisados estatisticamente e mostraram que 95\% (noventa e cinco por cento) dos professores, que responderam o questionário, informaram que não tinham conhecimentos sobre o Scratch e 5\% (cinco por cento) disseram que tinham algum conhecimento sobre a ferramenta. Desses professores, $71 \%$ (setenta e um por cento) reportaram que a oficina proporcionou uma boa contribuição para sua formação, 24\% (vinte e quatro por cento) disseram que contribuiu totalmente e $5 \%$ (cinco por cento) relataram pouca contribuição para sua formação. Dentre estes professores, $87 \%$ (oitenta e sete por cento) pretendem aplicar essa oficina nas escolas, no entanto, $13 \%$ (treze por cento) não tem essa pretensão. Quanto às estruturas das escolas para aplicação das oficinas, $51 \%$ (cinquenta e um por cento) dos professores ponderaram que as mesmas possuem laboratório de informática equipados com computadores e internet para realização das oficinas.

Quanto ao nível de satisfação em ter participado da oficina, 60\% (sessenta por cento) responderam satisfeito, $27 \%$ (vinte e sete por cento) muito satisfeito e $13 \%$ (treze por cento) pouco satisfeito, conforme ilustra a Figura 1. Foi também questionada como os professores avaliaram os seguintes itens referentes às oficinas: Objetivos; Conteúdo; Sequência; Tecnicamente; Grau de Dificuldades; Duração; Método de aplicação da oficina; e Informação. Para estes itens foram pedidos para os mesmos marcasse entre Excelente, Bom, Regular ou Ruim. O gráfico da Figura 2 apresenta estes resultados. 


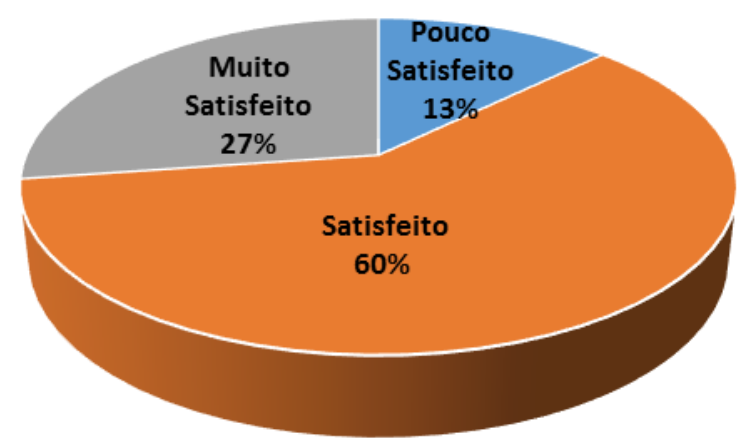

Figura 1: Nível de Satisfação das oficinas de Scratch.

\begin{tabular}{|c|c|c|c|c|c|c|c|c|}
\hline \multicolumn{9}{|l|}{$\begin{array}{l}45 \\
40\end{array}$} \\
\hline \multicolumn{9}{|l|}{35} \\
\hline \multicolumn{9}{|l|}{30} \\
\hline \multicolumn{9}{|l|}{25} \\
\hline \multicolumn{9}{|l|}{20} \\
\hline \multicolumn{7}{|l|}{10} & \multicolumn{2}{|c|}{15} \\
\hline \multicolumn{9}{|l|}{5} \\
\hline 0 & & & & & & & & 1 \\
\hline & Objetivos & Conteúdo & Sequência & $\begin{array}{c}\text { Tecnicame } \\
\text { nte }\end{array}$ & $\begin{array}{c}\text { Dificuldade } \\
\mathrm{s}\end{array}$ & Duração & Método & Informação \\
\hline Excelente & 26 & 22 & 13 & 16 & 1 & 6 & 11 & 21 \\
\hline Bom & 29 & 29 & 39 & 35 & 23 & 24 & 37 & 32 \\
\hline - Regular & 0 & 4 & 3 & 4 & 29 & 21 & 7 & 2 \\
\hline Ruim & 0 & 0 & 0 & 0 & 2 & 4 & 0 & 0 \\
\hline
\end{tabular}

Figura 2: Avaliação dos itens das oficinas de Scratch.

Quanto aos objetivos da oficina ministrada, 47.3\% dos professores classificaram como excelente e $52.7 \%$ como boa. Com relação ao conteúdo, $40 \%$ consideram excelente, $52.7 \%$ como boa e $7.3 \%$ regular. Na avaliação da sequência da oficina, $23.6 \%$ consideram excelente, $71 \%$ como boa e $5.4 \%$ como regular. Na avaliação dos aspectos técnicos, $29 \%$ ponderaram como excelente, $63.6 \%$ boa e $7.4 \%$ regular. Na avaliação da duração, $10.9 \%$ consideram excelente, $43.6 \%$ boa, $38.2 \%$ regular e $7.3 \%$ ruim, esse percentual estava dentro do esperado já que os professores relataram que almejavam mais tempo para a realização da oficina. $\mathrm{Na}$ avaliação do grau de dificuldade da oficina, $11 \%$ classificaram como excelente, $41.8 \%$ como boa, $38.2 \%$ como regular e $9 \%$ como ruim. Esse percentual de regular e ruim era esperado pelo motivo que uma parte considerável dos professores teve sua primeira experiência com o Scratch e com o computador. No que refere ao método de aplicação das oficinas, $20 \%$ consideram excelente, $67.3 \%$ como boa e $12.7 \%$ como regular, e por fim, na avaliação das informações repassadas nas oficinas, $38.2 \%$ classificaram com excelente, $58.2 \%$ como boa e $3.6 \%$ como regular. Este resultado é gratificante para todos os participantes e a oficina conseguiu atingir os objetivos que foram propostos.

\subsection{A oficina Desplugada}

As atividades desenvolvidas contidas no livro "Computer Science Unplugged" têm o intuito de ensinar fundamentos da Ciência da Computação sem o uso do computador. 
Foram realizadas duas atividades proposta no livro. A primeira foi "A Mágica de Virar as Cartas - Detecção e Correção de Erro" e a segunda foi a "Transmissão de uma Mensagem com Segurança - Criptografia".

A primeira atividade consiste em mostrar aos alunos como o computador busca corrigir eventuais erros de arquivos corrompidos, essa atividade foi realizada através de uma mágica conforme descrita no livro. A segunda atividade consiste em ensinar o conceito de criptografia no envio de mensagens.

Para verificar se a atividade foi bem aceita, monitoramos o comportamento e grau de interesse dos professores. Além disso, após cada oficina, um questionário foi aplicado com o objetivo de verificar a fixação dos conhecimentos e possíveis dúvidas acerca do conteúdo apresentado. Tal prática permitiu avaliar o nível de assimilação dos conceitos e a necessidade de possíveis ajustes nas oficinas. As oficinas foram avaliadas por meio de uma avaliação qualitativa e quantitativa. A avaliação qualitativa consiste na aplicação de questionários com perguntas sobre a aplicação, interesse e compreensão das atividades realizadas. A avaliação quantitativa versava sobre perguntas objetivas referentes ao tema da atividade com vistas a mensurar a absorção do conteúdo apresentado. As subseções a seguir abordarão estas avaliações.

\subsubsection{Avaliação Qualitativa}

Em um primeiro momento, as atividades realizadas foram explicadas aos professores e, em seguida aplicadas conforme preconizava o livro-guia e foram observadas as possíveis dificuldades a serem corrigidas ou melhoradas.

$\mathrm{Na}$ avaliação qualitativa foram destinadas perguntas referentes aos pontos positivos, negativos, as dificuldades encontradas e sugestões de melhorias. Quanto aos pontos positivos, destacamos alguns que os professores reportaram: aplicação dos conhecimentos da informática de forma lúdica; as novidades do mundo da tecnologia; a descoberta de novos conhecimentos; a utilização da tecnologia em prol da educação; possibilidade de deixar as aulas mais atrativas; a forma como pode ser trabalhado diferentes conceitos da computação sem o uso do computador; e mudança de comportamento.

No que tange aos pontos negativos, o ponto destacado, foi o pouco tempo para a realização das oficinas. Os professores mencionaram a vontade de participar de outras oficinas com uma carga horária maior.

Com relação às dificuldades que os professores encontraram para participar das oficinas, foi reportado como principais empecilhos a falta de hábito com a utilização do computador; não ter conhecimento prévio do assunto e; falta de conhecimento tecnológico.

Sobre as sugestões de melhoria das oficinas, os professores destacaram dois pontos: aumentar o tempo da oficina e desenvolver uma apostila sobre a temática. Sobre aumentar o tempo, um professor destacou: "acredito que se tivéssemos mais tempo o aprendizado seria melhor e teríamos mais segurança para transmitir o conteúdo aos alunos". Sobre a apostila, foi desenvolvida e será entregue agora nas próximas oficinas. 
Em síntese, os resultados obtidos nas três oficinas realizadas foram bastante satisfatórios. Os professores tiveram excelente participação nas atividades e reagiu, em geral, de forma satisfatória a proposição do problema fornecido na atividade.

\subsubsection{Avaliação Quantitativa}

Alguns desafios na elaboração de uma metodologia para as oficinas foram enfrentados. Um deles foi definir um programa, envolvendo teoria e prática, que fosse apropriado para o curto período de duração da oficina e o outro, tornar a oficina divertida e agradável para os participantes. Ao final das oficinas, os professores foram questionados sobre seus conhecimentos prévios em Computação Desplugada, se pretendiam aplicar a oficina na escola e se a escola onde atual tem estrutura para executar a oficina.

De acordo com os resultados reportados, 95\% (noventa e cinco por cento) dos professores não tinham nenhum conhecimento sobre a temática da oficina, mesmo sem esse conhecimento prévio, $89 \%$ (oitenta e nove por cento) dos professores relataram que pretendem aplicar essa oficina nas escolas e $87 \%$ (oitenta e sete por cento) das escolas possuem estrutura para a realização da oficina. Esses dados podem ser observados na Tabela 1.

Tabela 1: Resultado do questionário de avaliação com os participantes.

\begin{tabular}{|l|c|c|c|c|}
\hline \multicolumn{1}{|c|}{ Perguntas } & \multicolumn{4}{c|}{ Respostas } \\
\cline { 2 - 5 } & $\begin{array}{c}\text { Quantidade } \\
\text { de Professores }\end{array}$ & \multicolumn{2}{c|}{ Porcentagem } \\
\cline { 2 - 5 } & Sim & Não & Sim & Não \\
\hline Conhecimento sobre Computação Desplugada & 3 & 52 & $5 \%$ & $95 \%$ \\
\hline Você pretende aplicar essa oficina nas escolas & 49 & 6 & $89 \%$ & $11 \%$ \\
\hline Sua escola tem estrutura para executar a oficina? & 48 & 7 & $87 \%$ & $13 \%$ \\
\hline
\end{tabular}

A Figura 3(a) ilustra o resultado da avaliação quanto à contribuição das oficinas para a formação dos professores. $71 \%$ (setenta e um por cento) dos professores avaliaram como boa contribuição, 24\% (vinte e quatro por cento) reportaram que contribuiu totalmente e $5 \%$ (cinco por cento) disseram que a contribuição foi pouca. $\mathrm{Na}$ Figura 3(b) é apresentado o nível de satisfação em ter participado da oficina, $\quad 60 \%$ (sessenta por cento) analisaram como satisfeito, 27\% (vinte e sete por cento) como muito satisfeito e $13 \%$ (treze por cento) como pouco satisfeito.
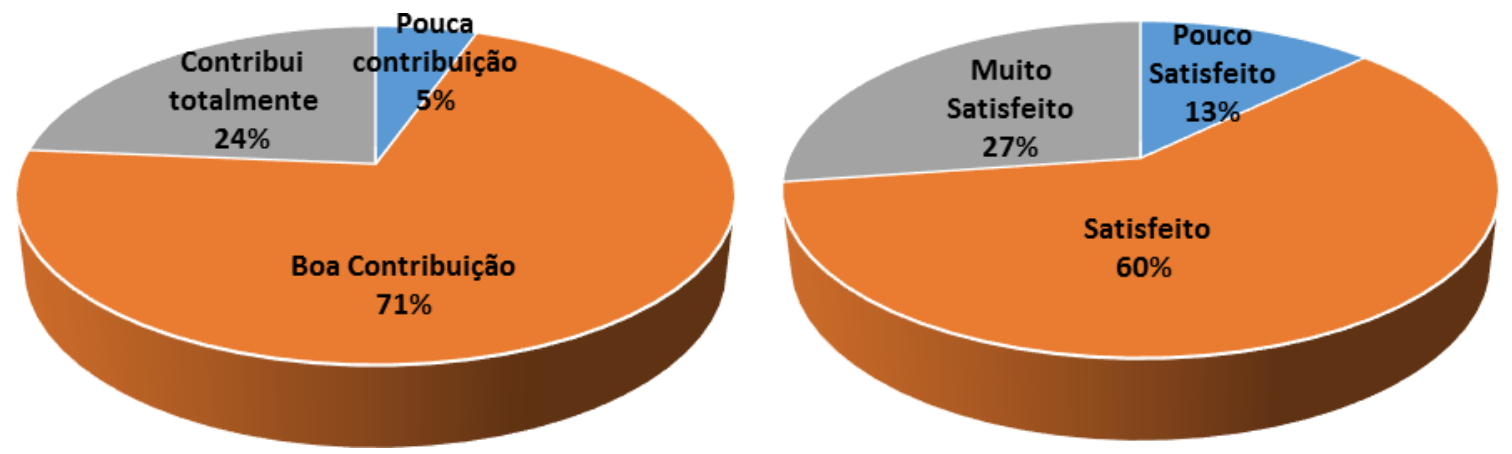

Figura 3: (a) Nível de contribuição e (b) Satisfação das oficinas de Computação Desplugada.

Em relação aos itens referentes às oficinas, a Tabela 2 expõe os dados analisados pelos professores. 
Tabela 2: Resultado da avaliação dos itens das oficinas de Computação Desplugada.

\begin{tabular}{|l|c|c|c|c|}
\hline & Excelente & Bom & Regular & Ruim \\
\hline Objetivos & $49 \%$ & $49 \%$ & $2 \%$ & $0 \%$ \\
\hline Conteúdo & $43.6 \%$ & $49 \%$ & $7.4 \%$ & $0 \%$ \\
\hline Sequência & $31 \%$ & $58.2 \%$ & $10.8 \%$ & $0 \%$ \\
\hline Tecnicamente & $32.7 \%$ & $58.3 \%$ & $9 \%$ & $0 \%$ \\
\hline Grau de dificuldades & $7.2 \%$ & $60 \%$ & $32.8 \%$ & $0 \%$ \\
\hline Duração & $12.7 \%$ & $49 \%$ & $34.5 \%$ & $3.8 \%$ \\
\hline Método de aplicação & $38.2 \%$ & $53.3 \%$ & $8.5 \%$ & $0 \%$ \\
\hline Informação & $34.5 \%$ & $58.2 \%$ & $7.3 \%$ & $0 \%$ \\
\hline
\end{tabular}

Ao analisar tais resultados, percebe-se que a Computação Desplugada apresentase como um método que pode ser utilizado pelos professores do ensino básico no desenvolvimento de habilidades e conhecimentos tão necessários na atualidade, como o pensamento computacional.

\section{Conclusão e Trabalhos Futuros}

A inovação na educação por intermédio da utilização de atividades lúdicas e dinâmicas é uma fonte significativa de atração e consolidação de conhecimento, em especial para alunos do ensino fundamental e médio.

A prática aqui relatada foi muito importante para iniciar um processo de amadurecimento e consolidação do ensino de fundamentos da computação para professores. Este artigo apresentou ainda, uma experiência referente à aplicação e avaliação das oficinas de Scratch e Computação Desplugada para professores do ensino fundamental e médio. Os resultados quantitativos e qualitativos refletem que essas oficinas foram bem aceitas pelos professores e que essas atividades auxiliam o aprendizado de conceitos de fundamentos da computação. Além disso, essas oficinas fortalecem os vínculos de interação entre professores e alunos de forma lúdica e interativa, o que reforça a troca de conhecimentos decorrentes dessas interações.

A concepção e realização da experiência, descrita neste trabalho, permitiu que os professores tivessem percepção teórica e prática do uso das tecnologias no ambiente escolar de forma inovadora. Tendo em vista os resultados alcançados com o estudo realizado, considera-se que os objetivos traçados foram alcançados.

São inúmeras as possibilidades pedagógicas com o uso do Scratch e da Computação Desplugada. O Scratch contribui para a contextualização dos conteúdos programáticos, com o uso de animações, jogos digitais e quiz. A Computação Desplugada contribui de forma a incluir o pensamento computacional nas atividades didáticas.

Este trabalho abriu inúmeras possibilidades de melhoria da atuação dos professores, haja vista que, apresentamos novas formas de ensino e aprendizagem. Ressalta-se que este trabalho está sendo pioneiro no estado e, apesar de refletir um estudo pontual, traz uma contribuição importante que é a possibilidade de trabalhar fundamentos da computação nas escolas pelos professores. Mais que conteúdos, eles puderam conhecer e exercitar práticas computacionais na realização dos desafios que lhes eram apresentados. 
Os resultados apresentados são satisfatórios e, por isso, em trabalhos futuros pretende-se aplicar a oficina e utilizar técnicas de avaliação numa amostra maior. Essas oficinas itinerantes ainda visitarão cinco municípios do estado e a expectativa é que duzentos professores sejam alcançados. Outra perspectiva de trabalhos futuros pretendida é que os professores participantes das oficinas repliquem essas oficinas para os alunos, com o suporte presencial e a distância dos instrutores.

Portando, considera-se este relato um passo em direção à disseminação dos fundamentos da computação no ensino fundamental e médio no estado do Rio Grande do Norte, tornando-o acessível à comunidade escolar.

\section{Agradecimentos}

Os autores agradecem a Coordenação de Aperfeiçoamento de Pessoal de Nível Superior (CAPES) pelo suporte parcial a esta pesquisa, ao Instituto Nacional de Engenharia de Software (INES), ao Conselho Nacional de Desenvolvimento Científico e Tecnológico (CNPq), ao PROEXT - MEC/SESu, ao Programa de Pós-Graduação em Sistemas Computacionais - PPgSC/UFRN, por toda infraestrutura oferecida, a coordenação do Curso de Aperfeiçoamento em Docência na Escola de Tempo Integral (parceria MEC/UFRN), e em especial a todos integrantes do Gamedu Research Lab.

\section{Referências}

Bell, T.; Witten, I. H.; Fellows, M. (2011) “Computer Science Unplugged - Ensinando Ciência da Computação sem o uso do computador". Tradução por: Luciano Porto Barreto. Disponível em: <http://csunplugged.org/books>. Acesso em: jun. de 2014.

Denning, P. J. (2004) "Great principles in computing curricula". In: XXXV ACM Technical Symposium on Computer Science Education - SIGCSE, p.336-341, Norfolk, Virginia, USA.

França, R. S.; Amaral, H. J. C. (2013) "Proposta Metodológica de Ensino e Avaliação para o Desenvolvimento do Pensamento Computacional com o Uso do Scratch". In: Workshop de Informática na Escola - WIE. p.179-188, Campinas - SP.

França, R.; Silva, W.; Amaral, H. "Ensino de Ciência da Computação na Educação Básica: Experiências, Desafios e Possibilidades”. In: XX Workshop de Educação em Computação - WEI. Curitiba, PR.

Pereira Júnior, J.; Rapkiewicz, C. E.; Delgado, C.; Xexeo, J. A. M. (2005) "Ensino de Algoritmos e Programação: Uma Experiência no Nível Médio". XIII Workshop de Educação em Computação - WEI. São Leopoldo, RS.

Sant'Anna, H. C.; Neves, V. B. (2012) "Scratch Day UFES: oficina itinerante de introdução a programação para professores". In: IV Simpósio Hipertexto e Tecnologia na Educação, Recife - PE.

SBC - Sociedade Brasileira de Computação. (2011) "A Computação como educação básica". In: Revista da Sociedade Brasileira de Computação. Porto Alegre: Giornale Comunicação Empresarial. 